\title{
Clays and modified clays in remediating environmental pollutants
}

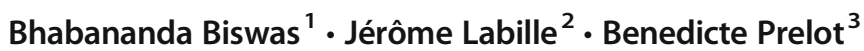

Published online: 23 July 2020

(C) Springer-Verlag GmbH Germany, part of Springer Nature 2020

Clay mineral is a layered hydrated aluminosilicate that makes up fine-sized particles $(<2 \mu \mathrm{m})$ in rock, sediment, and soils. Clay is a major reactive component of soil and surface water, where it plays an important role in determining the fate of contaminants, such as trace elements and organic pollutants (Schoonheydt et al. 2018). As a result of the ability of these minerals to adsorb a wide variety of these substances, both the lamellar and porous structures of natural and modified clay varieties (e.g., organically treated, acid-activated, pillared, nanocomposites, layered double hydroxides, among others), have long been of interest to understand their diffusion or for remediation purposes. However, several research aspects remain of special importance, in particular, the synthesis and characterization of new clay materials, the physicochemical behavior of pollutant adsorption in natural environments, and the biocompatibility and reusability of the clays and modified clays (Biswas et al. 2019).

Considering this field of research, the "Euroclay 2019" conference that is the meeting of the European Clay Groups Association (ECGA) jointly with the 56th annual meeting of the Clay Minerals Society (CMS) and the 6th Mediterranean Clay Meeting (MCM) hosted a session titled "The role of clays and modified clays in remediating environmental pollutants" on 1-5 July 2019 in Paris, France. The 2-day long session was delivered with 18 oral and 40 poster presentations, while Dr. Lydie Le Forestier, University of Orléans, was addressed as the keynote lecture. They presented various fundamental and applied aspects of environmental

Responsible editor: Philippe Garrigues

Benedicte Prelot

benedicte.prelot@umontpellier.fr

1 Future Industries Institute, University of South Australia, Mawson Lakes, SA 5095, Australia

2 CNRS, IRD, INRAe, Coll France, CEREGE, Aix Marseille University, Aix-en-Provence, France

3 Institute Charles Gerhardt, Montpellier University, Montpellier, France applications of smectite, halloysite, kaolinite, layered double hydroxides (LDHs), and their modified materials.

This special issue of Environmental Science and Pollution Research (ESPR) journal aims to publish some of the research presented at this session. All the submitted manuscripts went under vigorous peer-reviewing process according to the journal's policies, while the decision of the acceptance for the publication was taken by the core editors of the journal.

The articles presented in this special issue deal with different aspects of pollutant remediation by clays. As a local, abundant, and inexpensive resource, clays and modified clays have been investigated as potential adsorbent materials in water treatment processes for the removal of pollutant. A high specific surface area coupled with high reactivity makes clays promising solutions for this rising environmental concern (Cavallaro et al. 2020). In this special issue, an article by Aziz et al. (2019) presents research work on the effectiveness of a natural saponite from the Sulaimani region of Iraq for the removal of cadmium (Cd) from industrial wastewater. The authors performed adsorption experiments under varying conditions, which showed the high potential of saponite for the removal of $\mathrm{Cd}^{2+}$ in real wastewater samples. In a second article, Slatni et al. (2020) present the synthesis of a mesoporous silica obtained from a natural local kaolin deposit in Guelma province, Algeria. The synthesized material has been characterized and studied as an adsorbent for the removal of dye from textile effluent, showing promising decoloration efficiency.

The characterization of the clay material is a key step to better understand and optimize the desired properties in the targeted application. In an article presented here, Reijonen et al. (2020) present the interest of X-ray computed tomography to characterize the textural and structural properties of a bentonite-based geomaterial intended for use in the geological disposal of radioactive waste. This approach provides an in situ, non-destructive, and 3D analysis of the bentonite that enables to assess its long-term sealant performance in the repository.

Modification of the mineral structure is an interesting approach to adjust the characteristics of the particles, particularly 
their surface charge which often drives interfacial reactions with the surrounding components (Sposito 2004). In their article, Zhu et al. (2020) studied the effects of aluminum (Al) substitution on the surface charge of colloidal goethite particles. They followed both experimental and modeling approaches, using proton titration and multisite surface complexation MUSIC model. This dual approach allowed a specific understanding of the charging behavior of Al-substituted goethite.

We, the guest editors, believe that this special issue is delivered with the publication of quality research underpinned by various aspects of applied clay science in remediating environmental pollutants. There might be scope left to cover few additional aspects of clay-based environmental remediation; ecotoxicity and regeneration of modified clays are one of them. We can anticipate those aspects be studied and read by other journal issues.

As the co-conveners of the Euroclay 2019 session, we thank all the presenters and those who submitted abstract but could not attend the conference. We also thank the conference organizing committee for their contributions to hosting this session. We express our sincere gratitude to Robert Duran, the editor, ESPR, for his direct involvement in the peerreviewing process and handling of manuscripts submitted for this issue. We thank Philippe Garrigues, editor-in-chief, $E S P R$, for giving us the chance to host this special issue in this journal. We are also thankful to all editorial assistants, in particular, Fanny Creusot and Florence Delavaud, for their excellent support service for managing and handling manuscripts, communicating, and publishing this special issue.

\section{References}

Aziz BK, Shwan DMS, Kaufhold S (2019) Characterization of Tagaran natural clay and its efficiency for removal of cadmium (II) from Sulaymaniyah industrial zone sewage. Environ Sci Pollut Res. https://doi.org/10.1007/s11356-019-06995-x (this issue)

Biswas B, Warr LN, Hilder EF, Goswami N, Rahman MM, Churchman JG, Vasilev K, Pan G, Naidu R (2019) Biocompatible functionalisation of nanoclays for improved environmental remediation. Chem Soc Rev 48:3740-3770

Cavallaro G, Fakhrullin R, Pasbakhsh P (eds) (2020) Clay nanoparticles: properties and applications. Elsevier Inc., Amsterdam, p 368. https:// doi.org/10.1016/C2018-0-00293-5
Reijonen HM, Kuva J, Heikkilä P (2020) Benefits of applying X-ray computed tomography in bentonite based material research focussed on geological disposal of radioactive waste. Environ Sci Pollut Res. https://doi.org/10.1007/s11356-020-08151-2 (This issue)

Schoonheydt RA, Johnston CT, Bergaya F (eds) (2018) Surface and interface chemistry of clay minerals, 9. Elsevier B.V, Amsterdam, p 410

Slatni I, Elberrichi FZ, Duplay J, Fardjaoui NEH, Guendouzi A, Guendouzi O, Gasmi B, Akbal F, Rekkab I (2020) Mesoporous silica synthesized from natural local kaolin as an effective adsorbent for removing of acid red 337 and its application in the treatment of real industrial textile effluent. Environ Sci Pollut Res. https://doi. org/10.1007/s11356-020-08615-5 (This issue)

Sposito G (2004) The surface chemistry of natural particles. Oxford University Press, New York

Zhu S, Zhang P, Liang Y, Wang M, Xiong J, Tan W (2020) Effects of aluminum substitution on the surface charge of colloidal goethite particles: experiments and MUSIC modeling. Environ Sci Pollut Res. https://doi.org/10.1007/s11356-020-07793-6 (This issue)

Publisher's note Springer Nature remains neutral with regard to jurisdictional claims in published maps and institutional affiliations.

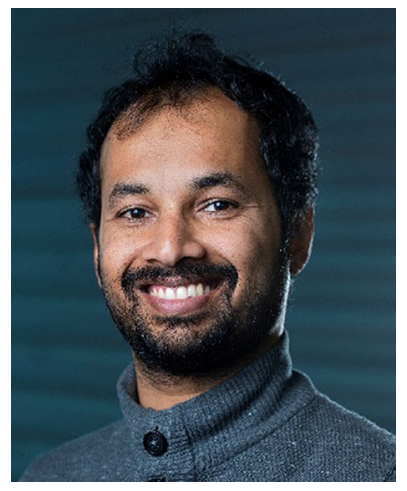

Bhabananda Biswas holds a $\mathrm{Ph}$.D. environmental bioremediation science. He obtained his $\mathrm{Ph} . \mathrm{D}$. from the University of South Australia in 2017. He has been working as a post-doctoral research fellow at the Future Industries Institute, University of South Australia. His current research is about clay-microbial interaction and synthesizing green nanomaterials for environmental applications. He has been cosupervising four $\mathrm{Ph} . \mathrm{D}$. and visiting students in the field of functionalized clays and the use of clay-supported iron and copper nanoparticles for wastewater cleanup. He published 28 research articles and book chapters in the area of modified clays, nanoparticles-clay composite, claymicrobial interactions, chemical pollutants in soil and water, and remediation technologies for environmental contamination. He received several recognitions for interdisciplinary research on clay-based nanocomposites, such as a top ten "Fresh Scientist" in South Australia and a profile spotlight in the magazine Elements. He contributes to the journal Frontiers in Environmental Science in the Toxicology, Pollution and the Environment section as the review editor as well as several other peer-reviewed journals as the reviewer. 


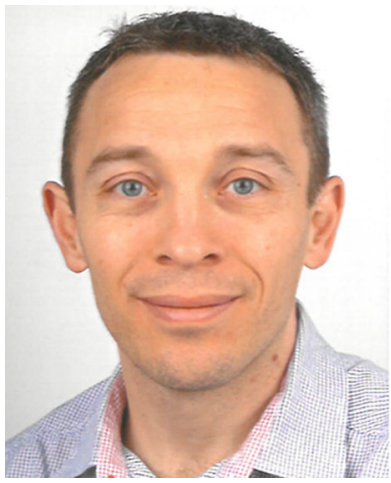

Jérôme Labille has a Ph.D. in environmental geosciences. He is a senior scientist at French National Scientific Research Center CNRS. His researches in CEREGE lab, Aix-Marseille Université, France, relate to the transfer of particulate matter in aqueous environment, with a particular focus on natural colloids and associated pollutants such as manufactured nanoparticles and organic pollutants. He studies the interfacial physicochemical mechanisms that govern the dynamic of aggregation, dispersion, and deposition of particles in aquatic systems and saturated porous media. He published 50 articles in this field of research that includes the role of clays in the fate of environmental pollutants. He coordinated different research programs on the heteroaggregation of manufactured nanoparticles with clays (ERA-NET SIINN Nanoheter 2013-2016), the adsorption of organic pollutants on clays in surface water (AFB Medimpacton 2018-2019) or the environmental risk associated to engineered nanoparticles used in cosmetics (Labex Serenade 2015-2019). He is a member of the administrative council of the French Clay group GFA.

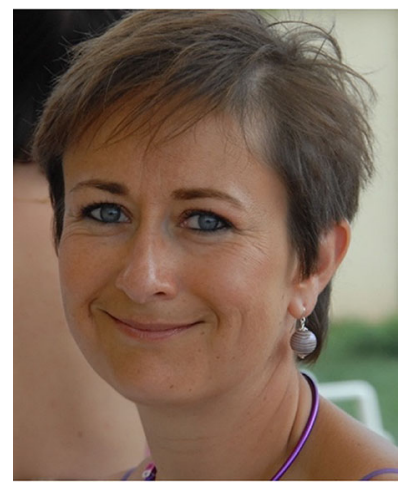

Benedicte Prelot is a senior scientist at the French National Center for Scientific Research (CNRS). Graduated from School of Geology (Nancy), and with a Ph.D. (INP Lorraine), she started in 2003 her academic carrier at Institut Charles Gerhardt de Montpellier, University Montpellier, France. Her researches are related to interfacial properties and surface reactivity at the solid/liquid interfaces, in colloidal systems and nanostructured and/or hybrid materials, via the use of molecules probes. This concerns a large variety of systems, with nanoparticles (iron, titanium oxides, etc.), porous materials, lamellar (LDH, clays), hybrids, and complexing polymers with various processes such as adsorption, exchange, and complexation of different polluting ions and molecules (heavy metals, radionuclides, dyes, drugs etc.). Lastly, she has developed dedicated calorimetric approaches to evidence adsorption driving forces. She has supervised more than $40 \mathrm{Ph} . \mathrm{D}$., postdocs, master students, and research engineers. She is a co-founder of the French Association of Adsorption and is an associate editor for Chemical Papers and Adsorption Science \& Technology. She has published about 75 papers in refereed journals and books and is a co-author of 2 patents. Her work has been presented in more than 30 invited conferences, seminars, and 80 oral communications in international conferences. 